\title{
Studi Tentang Game Usability Pada In-app Game Untuk Meningkatkan Engagement Pengguna E-commerce
}

\author{
Hendra Dinata $^{{ }^{*}}$, Melissa Angga ${ }^{2}$ \\ ${ }^{1,2}$ Program Studi Teknik Informatika, Universitas Surabaya, Surabaya, Jawa Timur \\ Email: ${ }^{1 *}$ hdinata@staff.ubaya.ac.id, ${ }^{2}$ melissa@staff.ubaya.ac.id
}

(Naskah masuk: 1 Jul 2021, direvisi: 18 Okt 2021, diterima: 25 Okt 2021)

\begin{abstract}
Abstrak
Maraknya perdagangan online di Indonesia memicu kebutuhan akan hadirnya strategi yang mampu mengadaptasi perkembangan TI secara lebih kreatif bagi suatu platform agar dapat lebih merangkul dan mengikat penggunanya. Salah satu strategi tersebut adalah dengan menghadirkan in-app game untuk menjaga agar pengguna dapat secara konsisten hadir dan mengakses platform tersebut. Efektivitas in-app game dalam meningkatkan engagement sangat bergantung pada usability dari In-app game itu sendiri, sehingga dalam penelitian ini akan disusun suatu evaluasi heuristik yang mempertimbangkan game usability dan juga teori flow untuk menguji user engagement pada game Shopee Candy. Objektif evaluasi tersebut meliputi 7 aspek yaitu ketersediaan mekanisme yang memudahkan pemain belajar dan menikmati alur permainan, kemudahan untuk dimainkan tetapi cukup menantang, kemudahan pemain mengenali tindakannya, grafis yang menarik, kemudahan akses, sisi mobilitas dan penambahan aspek ke-7 yaitu keterhanyutan pemain. Proses pengujian melibatkan sejumlah responden yang memiliki pengalaman bermain game Shopee Candy yang akan mengisi survei sesuai evaluasi heuristik yang telah disusun. Berdasarkan uji validitas terhadap setiap objektif, beberapa pertanyaan pada objektif pertama dan kedua dinyatakan tidak valid dengan nilai r di bawah 0,3. Kemudian berdasarkan uji reliabilitas pada setiap objektif, nilai Cronbach menunjukkan bahwa setiap objektif dapat diandalkan dengan objektif yang agak kurang adalah pada objektif grafis yang menarik dan kemudahan akses. Secara umum dapat disimpulkan game Shopee Candy berhasil menjalin user engagement yang terukur dari 7 aspek yang dievaluasi dan pengembang game perlu memberikan perhatian lebih dalam menyusun mekanisme yang dapat membantu pemain belajar dan memahami alur permainan serta kemudahan dalam kustomisasi dan mobilitas.
\end{abstract}

Kata Kunci: usability, game mobile, e-commerce, in-app game

\section{Study on Game Usability in In-app Games to Increase E-commerce User Engagement}

\begin{abstract}
The growth in popularity of online commerce in Indonesia triggers the need for a more creative strategy to adopt IT developments for a commerce platform to gain better binding and engagement from its users. One of these strategies is to introduce in-app games in order to maintain user consistent attendance and access. The effectiveness of in-app games in increasing user engagement depends on the usability of the In-app Game itself. This study will arrange a set of heuristic evaluations while considering game usability and flow theory to test user engagement in the Shopee Candy game. The objective includes 7 aspects, namely learning mechanisms that make it easier for players to learn and enjoy the gameplay, ease of play and interesting challenge, easiness of recognizing player actions, graphics attractiveness, ease of access, mobility side and for the addition the 7th aspect is based on the flow theory, the immerse effect. The testing process involves a number of respondents who have played the Shopee Candy game and fill out a survey according to the heuristic evaluation prepared. Based on the validity test of each objective, several questions on the first and second objectives were declared invalid with an $r$ value below 0.3. Then based on the reliability test on each objective, Cronbach's score shows that each objective is reliable with the aim of attractive graphics and ease of access found to be less reliable. In general, it can be concluded that the Shopee Candy game is successful in establishing measurable user engagement from the 7 evaluated aspects and game developers need to pay more attention in developing mechanisms that can help players learn and understand the flow of the game as well as ease of customization and mobility aspect.
\end{abstract}

Keywords: usability, mobile game, e-commerce, in-app game 


\section{PENDAHULUAN}

Perdagangan yang terjadi di Indonesia banyak dilakukan melalui jalur online atau yang biasa disebut dengan $e$ commerce. Untuk perdagangan retail saja, di akhir tahun 2020, nilai transaksi perdagangan online di Indonesia diperkirakan mencapai USD 40 miliar [1]. Pelaksanaan perdagangan online dapat berlangsung baik dengan menggunakan platform e-commerce tertentu maupun juga dapat menggunakan media sosial dan aplikasi pesan instan lainnya sebagai medianya. Khusus untuk platform $e$ commerce yang ada di Indonesia, hingga Q4 tahun 2020, tercatat 5 platform yang paling mendominasi jika ditinjau dari jumlah kunjungan, yaitu Shopee, Tokopedia, Bukalapak, Lazada dan Blibli [2].

Kehadiran e-commerce telah sejak lama diketahui membawa dampak perubahan pola jual-beli antara penjual dan pembeli. Tetapi lebih dari itu, e-commerce juga membawa dampak pada perspektif bisnis itu sendiri dari semula "keunggulan produksi" yang berfokus pada produk, menjadi bergeser kepada "keintiman pelanggan", yaitu hubungan yang dibangun dengan pendekatan emosi antara penjual dan pembeli [3].

Sebagai salah satu platform e-commerce terbesar di Indonesia, Shopee tampak berusaha mengoptimalkan sumber daya dan teknologi TI yang ada. Salah satu terobosan strategi yang diterapkan oleh Shopee dalam rangka mempertahankan jumlah kunjungan pengguna di aplikasi adalah dengan menghadirkan in-app game. In-app game adalah sebuah aplikasi game yang ditambahkan dan kemudian menjadi bagian dari aplikasi induk. Jadi, kehadiran game di dalam aplikasi $e$-commerce memang secara spesifik ditujukan untuk menarik minat pengguna agar terus bertahan menggunakan platform tersebut, dan dengan pemberian reward tertentu akan mendorong pengguna untuk bertransaksi di dalam platform tersebut. Keberhasilan suatu in-app game diawali dengan keterikatan pemain terhadap game tersebut yang ditunjukkan dengan kehadirannya dalam platform tersebut untuk bermain in-app game yang pada akhirnya juga akan menunjukkan keterikatan user terhadap platform tersebut.

Agar game yang dihadirkan di dalam aplikasi e-commerce tersebut dapat mencapai tujuannya, maka perlu diperhatikan hal-hal yang terkait dengan user experience. Oleh karena game yang dihadirkan tersebut adalah game yang berbasis mobile, yaitu game tersebut dimainkan pada sebuah perangkat smartphone yang memiliki sejumlah keterbatasan seperti ukuran layar yang terbatas, konektivitas dan cara kontrol, maka hal ini menjadi tantangan tersendiri bagi pengembangnya $[4,5]$. Dalam hal ini, usability memegang peranan yang cukup sentral karena keterikatan (engagement) user ternyata sangat dipengaruhi oleh usability dari apps itu sendiri dan pengguna mobile device dikenal lebih tidak sabar dan lebih sulit mentoleransi pengalaman (user experience) yang kurang menyenangkan [6, 7]. Hal ini dapat dimaklumi karena secara fisik perangkat mobile memiliki berbagai keterbatasan dan ketergantungan misalnya dari sisi ukuran layar yang relatif lebih kecil dan tingkat sensitivitas layar sentuh yang berbeda pada tiap jenis dan merek perangkat.
Masalah dalam usability sendiri bukan hal yang dapat dengan mudah ditemukan. Terkadang masalah itu tidak tampak dari awal saat evaluasi sehingga lolos dari pengamatan, bahkan saat telah dilakukan tes awal dengan calon user. Tetapi saat telah diluncurkan dan dipakai berulang kali, keberadaannya baru dirasakan dan semakin lama pengaruhnya dirasakan semakin mengganggu dan merusak pengalaman user dalam berinteraksi [7]. Masalah dalam suatu in-app game yang merupakan bagian dari suatu platform jika tidak dikelola dengan baik pada akhirnya dapat menjadi bumerang karena bukannya meningkatkan keterikatan user (user engagement) terhadap platform tersebut, tetapi berpotensi meningkatkan kejengkelan user terhadap platform tersebut.

Menimbang pentingnya usability terkait user engagement, penelitian ini akan mencoba melakukan evaluasi terhadap usability dari game Shopee Candy yang terdapat pada platform e-commerce Shopee. Usability yang akan dievaluasi mengacu kepada game usability, khususnya mobile game usability. Hasil dari evaluasi ini diharapkan dapat memberikan gambaran bagi para pengembang game dan memberikan input yang berguna tentang bagaimana suatu aplikasi game pada e-commerce sebaiknya didesain agar dapat memenuhi preferensi dari penggunanya yang dengan demikian meningkatkan level usability dan user experience yang pada akhirnya akan menambah keterikatan user (user engagement).

Pada bagian berikutnya dari artikel ini akan dipaparkan tinjauan pustaka atas evaluasi heuristik yang akan diterapkan dalam penelitian ini, untuk selanjutnya dieksekusi lebih lanjut dengan penyusunan daftar kuesioner sebagai komponen penting dari evaluasi. Hasil dari survei serta pembahasan akan disajikan pada bagian selanjutnya. Dan terakhir, seluruh hasil analisis akan disajikan dalam suatu kesimpulan dan saran untuk dilanjutkan dalam penelitian berikutnya.

\section{EVALUASI HEURISTIK GAME MOBILE}

Game mobile pada umumnya sengaja dirancang sematamata untuk tujuan hiburan semata. Walaupun demikian, tidak menutup kemungkinan game mobile juga dapat digunakan sebagai sebuah media untuk keperluan iklan dan pemasaran [8]. Sejak dijadikannya sebuah game mobile sebagai bagian dari strategi dalam menarik konsumen oleh platform $e$ commerce, maka kesuksesan dari strategi ini juga ditentukan dari kualitas game itu sendiri.

Jika mengacu pada standar Internasional ISO 9126, usability dapat dipandang sebagai suatu kemampuan dari dalam diri suatu produk agar dapat dimengerti, mudah dipelajari, dan dapat digunakan oleh penggunanya dalam konteks tertentu. Telah lama pentingnya prinsip usability yang diterjemahkan dalam bentuk user interface dan user experience yang dapat menjadi daya tarik bagi pengguna disadari oleh berbagai pihak [9]. Dan secara klasik masalah terkait usability juga telah lama menjadi perhatian dan menempati porsi penting dalam perancangan suatu sistem.

Game seperti juga sistem pada umumnya dapat mengalami masalah dalam perancangan user interface maupun user 
experience terkait usability. Secara umum, untuk mendeteksi dengan tepat masalah usability yang sering dihadapi oleh suatu sistem, telah dirumuskan 10 set evaluasi heuristik usability terhadap desain antar muka sebuah software [10]. Walaupun telah ada, tetapi perlu diingat bahwa kehadiran 10 langkah evaluasi heuristik usability terhadap desain antar muka sebuah software telah lama diluncurkan yaitu lebih dari 20 tahun lalu dan hal penting yang perlu dicermati adalah sejak peluncurannya pada tahun 1999 yang lampau, perkembangan dunia digital telah sangat banyak mengalami kemajuan menjadi teknologi yang ada pada saat ini khususnya terkait aplikasi mobile dan pengembangan aplikasi game di perangkat bergerak. Karena itulah berbagai penyesuaian perlu dilakukan jika prinsip tersebut akan diterapkan terhadap sebuah objek game.

Beberapa panduan heuristik tentang game telah dikemukakan sebelumnya oleh sejumlah peneliti dan dapat menjadi panduan awal dalam pelaksanaan evaluasi. Pada Tabel 1 dapat dilihat rangkuman dari sejumlah langkah heuristik yang telah dikemukakan oleh para peneliti sebelumnya.

Tabel 1. Sumber Penelitian Sebelumnya

\begin{tabular}{ll}
\hline Sumber & \multicolumn{1}{c}{ Evaluasi } \\
\hline$[11]$ & 40 heuristik untuk usability game \\
\hline$[12]$ & $\begin{array}{l}\text { Mengembangkan HEP } \quad \text { (Heuristic } \\
\text { Evaluation for Playability) yang meliputi } 4 \\
\text { kategori: game play, game story, game } \\
\text { mechanics, game usability }\end{array}$ \\
\hline
\end{tabular}

[13] 10 set heuristik khusus untuk video game dengan pemain tunggal sebagai penyempurnaan dari sebelumnya $[11,12]$

[14] 10 langkah heuristik khusus untuk mengevaluasi usability game multi pemain

[15] 49 langkah heuristik untuk usability game dalam 2 kategori yaitu alur permainan dan antar muka virtual

[16] Evaluasi heuristik khusus usability game mobile multi pemain

Secara umum berbagai langkah heuristik yang telah dihasilkan dari berbagai penelitian dapat mengakomodasi kebutuhan penilaian usability suatu game. Hal ini ditunjukkan dengan kesesuaian hasil uji coba pemakaian metode tersebut dengan hasil review dari pemain yang didapatkan dari berbagai lembaga peranking. Walau demikian, berbagai langkah heuristik tersebut belum mempertimbangkan situasi saat sebuah game tidak berdiri sendiri tetapi merupakan bagian dari suatu sistem $e$-commerce.

\section{METODOLOGI PENELITIAN}

Pada penelitian ini akan dilakukan evaluasi heuristik pada aplikasi game "Shopee Candy" yang dapat ditemukan pada platform e-commerce Shopee. Game ini memiliki kesamaan game play seperti game Bejeweled, sebuah game puzzle klasik terkenal yang telah ada sejak 2001 dan memiliki tujuan permainan mencocokkan objek yang sama.

Evaluasi heuristik akan didasarkan pada hasil penelitian sebelumnya yang mengenai evaluasi heuristik yang dilakukan terhadap sebuah game mobile "Hay Day" [17]. Terdapat 6 hal utama yang menjadi objektif evaluasi yang dirangkum dari berbagai penelitian sebelumnya $[12,13,16]$. Keenam hal yang menjadi objektif evaluasi heuristik tersebut adalah:

(M) Game harus memiliki mekanisme yang memfasilitasi proses belajar si pemain dan alur permainan secara umum (melibatkan 12 butir pertanyaan)

(K) Game harus mudah dan menyenangkan untuk dimainkan, tetapi memiliki kerumitan untuk mempertahankan keterlibatan pemain (melibatkan 13 butir pertanyaan).

(F) Pemain harus dapat mengidentifikasi tindakannya dalam permainan dan umpan balik (melibatkan 4 butir pertanyaan)

(G) Game ini harus memiliki grafis yang menarik tanpa mempengaruhi alur permainan dan dapat dikustomisasi (melibatkan 9 butir pertanyaan)

(A) Game harus dapat diakses oleh semua orang atau pemain (melibatkan 4 butir pertanyaan)

(B) Permainan harus cocok untuk mobilitas (melibatkan 4 butir pertanyaan)

Serangkaian pertanyaan untuk masing-masing objektif mengacu pada set heuristik objektif dari penelitian terdahulu [17]. Mengingat penelitian ini juga meneropong mengenai user engagement platform yang memiliki keterkaitan erat dengan user engagement dalam in-app games dan bukan hanya mengukur masalah usability, maka perlu ditambahkan beberapa pertanyaan untuk mempertajam evaluasi tentang user engagement. Walaupun tidak dapat dipungkiri bahwa usability sendiri adalah poin utama dalam peningkatan user engagement.

Mempertimbangkan evaluasi mengenai user engagement, maka pada poin heuristik kedua mengenai kemudahan dan kesenangan bermain, ditambahkan pertanyaan yang mengarah kepada perasaan bersemangat atau kalah saat menghadapi tantangan dalam game [18] serta kejelasan goal permainan $[18,19]$ untuk lebih menajamkan objektif dari poin tersebut.

Mengingat aplikasi game yang ditawarkan oleh Shopee bukanlah bagian dari core-business yang ditawarkan oleh platform ini, maka perlu juga diketahui sampai sejauh mana game tersebut dianggap merupakan game yang bagus namun tidak membuat pemakainya sampai pada taraf adiksi berlebihan [20, 21]. Ketika seseorang benar-benar terkait tetapi terlalu intens melibatkan diri dalam aliran pengalaman bermain sebuah game atau dapat disebut terhanyut dalam pengalaman bermain, hal tersebut diklaim dapat menimbulkan hal negatif seperti tidak acuh terhadap diri sendiri dan mempengaruhi hubungan sosialnya [22]. 
Bagaimana seorang pemain terhanyut dalam pengalamannya bermain sebuah game dengan melibatkan kesenangan, tantangan, perasaan, dan perilaku, biasanya diukur dengan menggunakan Teori Flow [23]. Studi tentang pengukuran pengalaman terlibat penuh dan terhanyut di dalamnya menggunakan aplikasi game mobile dengan Teori Flow telah dilakukan sebelumnya dengan menggunakan 5 butir pertanyaan [24]. Evaluasi tentang keterhanyutan ini penting dalam menentukan seberapa jauh user engagement yang sehat, untuk itu pada penelitian ini akan ditambahkan poin objektif ke-7 yaitu "(P) Pemain terhanyut dalam pengalaman bermain game".

Pengumpulan data dalam penelitian ini melibatkan sejumlah responden dari berbagai kelompok usia dan sembarang gender yang memiliki pengalaman memainkan game Shopee Candy sebelumnya. Responden selanjutnya diminta untuk mengisi serangkaian pertanyaan sesuai 7 objektif set evaluasi heuristik yang telah ditentukan. Pertanyaan-pertanyaan tersebut dibagikan dalam bentuk kuisioner online menggunakan Google Form untuk kemudian diolah data dengan menggunakan aplikasi SPSS. Sebelum menjawab butir-butir pertanyaan menggunakan Skala Likert, responden mendapatkan kesempatan ulang untuk kembali memainkan game Shopee Candy untuk menyegarkan ingatan tentang pengalaman bermain game tersebut. Daftar pertanyaan yang diajukan kepada para responden dapat dilihat pada Lampiran 1.

\section{HASIL DAN PEMBAHASAN}

Pengumpulan data dilakukan melalui survei online selama 1 bulan dan mendapatkan 56 responden. Dari 56 data responden yang masuk, pada akhirnya hanya terjaring 37 responden yang eligible untuk mengikuti evaluasi ini, yaitu responden yang pernah masuk ke platform Shopee dan pernah memainkan game Shopee Candy sebelumnya. Sebaran responden yang eligible tersebut adalah 8 pria dan 29 wanita yang pernah memainkan game Shopee Candy. Dari ke-37 responden tersebut, frekuensi pembelanjaan online melalui platform e-commerce Shopee dari responden tercatat sebagai berikut, sebanyak 18 orang berbelanja 1-2 kali dalam sebulan terakhir, 11 orang perbelanja 3-4 kali dalam sebulan terakhir, 7 orang dengan frekuensi belanja dalam sebulan terakhir sebanyak 5 kali atau lebih, dan 1 orang sisanya tidak pernah melakukan pembelanjaan.

Pada uji validitas terhadap objektif pertama yaitu "Game harus memiliki mekanisme yang memfasilitasi proses belajar si pemain dan alur permainan secara umum", didapati 3 butir pertanyaan di antaranya memiliki nilai $\mathrm{r}$ di bawah 0,3 sehingga dinyatakan tidak valid, yaitu butir pertanyaan M2, M4 dan M5 dengan nilai R masing-masing 0,285, 0,192, dan 0,155 . Demikian pula untuk objektif kedua, yaitu "Game harus mudah dan menyenangkan untuk dimainkan, tetapi memiliki kerumitan untuk mempertahankan keterlibatan pemain", didapati dua butir pertanyaan di antaranya tidak valid yaitu pertanyaan K8 dan K11 dengan nilai r masingmasing 0,194 dan 0,256.
Untuk uji reliabilitas pada masing-masing objektif, didapatkan semua nilai Cronbach seperti terlihat di Tabel 2 berikut di bawah ini. Pada tabel dapat dilihat bahwa objektif "Game ini harus memiliki grafis yang menarik tanpa mempengaruhi alur permainan dan dapat dikostumisasi" dan "Game harus dapat diakses oleh semua orang atau pemain" memiliki nilai di antara 0,4-0,5 sehingga demikian kedua objektif ini dapat diandalkan namun masih kurang dibandingkan dengan objektif-objektif lainnya.

\begin{tabular}{cr} 
Tabel 2. Uji Reliabilitas \\
\hline Objektif & Cronbach \\
\hline M & 0,784 \\
\hline K & 0,786 \\
\hline F & 0,736 \\
\hline G & 0,770 \\
\hline A & 0,546 \\
\hline B & 0,571 \\
\hline P & 0,859 \\
\hline
\end{tabular}

Game Shopee Candy merupakan game yang memang hanya dapat dimainkan melalui perangkat mobile dan tidak dapat dimainkan menggunakan komputer PC. Menghadirkan desain, alur permainan yang memberikan pengalaman menarik bagi penggunanya adalah hal yang sangat perlu diperhatikan bagi para pengembang game agar pengguna mau meluangkan waktu lebih banyak untuk bermain dengan game tersebut [25]. Demikian pula game yang dihadirkan Shopee pada aplikasi e-commerce mereka.

Kemudahan dalam mengakses game atau melakukan kontrol terhadap game, seringkali menjadi halangan utama pada para pengguna untuk mendapatkan aliran pengalaman dalam menikmati game [25]. Sebanyak 65\% di antara responden menganggap bahwa menu bantuan atau tutorial tidak dapat ditampilkan ulang. Padahal sebenarnya di dalam game ini telah disediakan menu bantuan tersebut. Ketidaksesuaian antara fakta dengan pengalaman user dapat terjadi karena desain UI yang kurang jelas sehingga menyebabkan pengguna kesulitan untuk menemukan menu tersebut atau malahan tidak tahu keberadaan menu tersebut yang mengakibatkan asumsi bahwa menu tersebut tidak ada. Bagaimanapun, menu bantuan sangat berguna, khususnya bagi pemain baru, untuk memperkenalkan mekanik game sehingga pengguna dapat memahami dan mulai dapat menggunakan game tersebut [26]. Hal ini walaupun tampak sederhana, tetapi perlu mendapat perhatian yang lebih dari pengembang game agar calon pengguna tidak mengalami kesulitan mempelajari permainan dan memutuskan untuk batal mencoba bermain.

Hal yang perlu diingat juga adalah bahwa perangkat mobile memiliki keterbatasan dalam hal ukuran layar dan cara control, terlebih jika dibandingkan dengan komputer PC. Aset-aset game, baik itu icon atau karakter harus dapat diletakkan pada layar dengan ukuran yang proporsional terhadap ukuran layar perangkat mobile. Pengguna harus diberikan kemudahan mengatur permainan dan diberikan kewenangan untuk melakukan kustomisasi baik itu terhadap 
audio, bahasa, cara kontrol, dan lainnya [4,5]. Apabila pengguna dari game Shopee Candy ini diberikan keleluasaan lebih dalam hal melakukan kustomisasi, tentu ini dapat menumbuhkan sikap positif pengguna agar terus setia memainkan game ini [25, 27, 28].

Selain daripada itu, untuk mempertahankan para pemainnya untuk terus memainkan game Shopee Candy, tantangan-tantangan terus diberikan di setiap levelnya. Pada butir pertanyaan K10, sebanyak 64,86\% responden menjawab setuju dan sangat setuju bahwa setiap tantangan yang diberikan tidak membosankan, dan 91,89\% menyatakan pada butir pertanyaan K12 bahwa tantangan yang ada sebenarnya membuat mereka tertarik untuk terus memainkan game Shopee Candy ini. Supaya pemain tidak merasa bahwa mereka hanya terhenti di suatu level tantangan yang terasa sama saja dan tidak berkembang, maka penting bagi developer sebuah game untuk menghadirkan satu catatan tentang progres kemajuan atas kemampuan si pemain [29]. Begitu pula pada game Shopee Candy ini, progres atas pencapaian dari pemain seharusnya dapat disajikan agar lebih memudahkan bagi pemain untuk melihat kembali dan membandingkannya.

Sementara itu pada objektif mengenai kecocokan game ini untuk mendukung mobilitas, hasil survei menunjukkan nilai reliabilitas sebesar 0,571. Salah satu poin yang dapat dicermati adalah tentang kemampuan game Shopee Candy ini untuk dapat menyimpan game dalam kondisi tertentu. Game Shopee Candy tidak dilengkapi dengan fitur untuk melakukan penyimpanan suatu kondisi di tengah-tengah permainan yang sedang berlangsung. Sebagai sebuah game mobile yang memang tidak dirancang agar pemainnya menghabiskan waktu yang lama untuk memainkannya, ketiadaan fitur penyimpanan dapat membawa seorang pemain dalam keadaan frustasi [29]. Pemain seharusnya dapat diberikan keleluasaan untuk menginterupsi jalannya permainan dari sebuah game mobile di tengah mobilitas kesehariannya.

Pada pengukuran objektif terakhir yaitu tentang pengalaman bermain $(\mathrm{P})$ dari pengguna, tidak semua responden setuju bahwa game ini dapat membawa pikiran pengguna tidak fokus pada dunia nyata. Pada butir pertanyaan P4 dan P5, nilai rata-rata atas jawaban ini hanyalah 3,56 dan 3,51 yang berarti bahwa responden tidak sepakat bahwa game ini benar-benar bisa menciptakan dunianya sendiri hingga lupa akan dunia nyata. Dalam hal ini berarti pihak pengembang game berhasil menghadirkan sebuah game yang dapat memberikan pengalaman bermain kepada penggunanya tanpa menciptakan adiksi berlebihan terhadap game tersebut. Aspek ini menunjukkan bahwa in-app game ini sehat untuk dimainkan dan baik dalam menjalin keterikatan pemain tanpa menimbulkan efek negatif dari keterikatan yang berlebihan.

\section{KESIMPULAN}

Dalam menghadapi persaingan di antara banyaknya platform e-commerce di Indonesia, Shopee sebagai salah satu penyedia platform e-commerce memiliki strategi khusus untuk mempertahankan jumlah kunjungan penggunanya.
Strategi tersebut adalah dengan menyediakan in-app game, salah satunya adalah game Shopee Candy. Keberhasilan strategi ini dapat tercapai jika user memiliki keterikatan yang baik dengan game tersebut.

Untuk mengetahui keberhasilan in-app game tersebut menjalin keterikatan user diadakan penelitian yang mengadopsi evaluasi heuristik mengenai usability game Shopee Candy dengan menggunakan 7 macam objektif pertanyaan. Ketujuh macam objektif pertanyaan itu meliputi pertanyaan mengenai mekanik game, tantangan dalam game, feedback dari game, grafik, aksesibilitas game, mobilitas, dan pengalaman bermain. Pertanyaan-pertanyaan terkait ketujuh objektif telah sesuai dengan penelitian sebelumnya untuk menilai usability game secara menyeluruh terkait aspek-aspek dari sebuah game dengan sedikit penyesuaian yang mempertimbangkan bahwa game yang dimainkan ini merupakan bagian dari platform E-commerce.

Evaluasi dilakukan dengan menyebarkan kuisioner dan diperoleh 37 responden yang valid. Para responden menjawab butir-butir pertanyaan yang ada berdasarkan pengalaman mereka sebelumnya.

Dari hasil evaluasi tersebut, dapat disimpulkan bahwa Game Shopee Candy ini berhasil menghadirkan sebuah pengalaman bermain bagi para pemainnya yang membuat para pemain ini menjadi tertantang dan ingin terus bermain yang berarti mampu menjalin user engagement pada game tersebut. Game Shopee Candy berarti mampu membawa pemain untuk hadir kembali di platform tersebut secara berkala. Hal ini terlihat dari hasil survei di mana $91.89 \%$ responden menyatakan setuju atau sangat setuju bahwa tantangan yang diberikan di dalam game ini membuat mereka ingin terus memainkan game ini.

Beberapa poin dapat dijadikan masukan penting bagi para pengembang game yaitu pentingnya penyajian fitur yang memberikan keleluasaan bagi pemain untuk melakukan kustomisasi atas icon, karakter, suara atau cara kontrol permainan. Demikian juga dengan kehadiran menu bantuan yang mudah terdeteksi dan menu penyimpanan di tengah permainan.

Penelitian ini juga terbatas pada jumlah responden yang hanya 37 responden. Pada pengembangan berikutnya, penelitian dapat dilanjutkan untuk mengukur pengaruh in-app game seperti Shopee Candy ini terhadap keinginan si pemain untuk berbelanja di aplikasi e-commerce tersebut dengan data driven dari jumlah responden yang lebih banyak.

\section{REFERENSI}

[1] Redseer. (2020). Indonesia E-commerce: Racing Ahead. [Online]. Diakses dari: https://redseer.com/newsletters/ indonesia-e-commerce-racing-ahead/ pada tanggal 16 Maret 2021

[2] Iprice. (2021). The Map of E-commerce in Indonesia [Online]. Diakses dari: https://iprice.co.id/insights/ mapofecommerce/en/ pada tanggal 16 Mar 2021

[3] MacGregor, R.C. \& Vrazalic, L. (2005). Role of SmallBusiness Strategic Alliances in the Perception of Benefits 
and Disadvantages of E-commerce Adoption in SME. London: Idea Group publishing

[4] Lee, Y.E. \& Benbasat, I. (2004). A Framework for the Study of Customer interface Design for Mobile Commerce. International Journal of Electronics and Communications, Vol. 8(3), pp. 79-102

[5] Lu, H.K., Lin, P.C. \& Lin, Y.C. (2016). A Study of the Factors Affecting the Purchase Intention on Mobile Game Apps. Journal of Advances in Information Technology, Vol. 7(4), pp. 239-244

[6] Sonnenberg, C. (2020). Mobile Media Usability: Evaluation of Methods for Adaptation and User Engagement. Journal of Media Management and Entrepreneurship, Vol. 2(1), pp. 86 - 107

[7] Nielsen, J. \& Budiu, R. (2013). Mobile Usability. New Riders, Berkeley, CA, United States of America

[8] Salo, J. (2010). Conceptualizing Mobile Game Advertising: Relationship between Different Game Types and Degree of Brand Exposure. Journal of Digital Marketing, Vol. 1, pp. 129-138

[9] Karat, C.M. (2005). A Business Case Approach to Usability Cost Justification for the Web. Cost-Justifying Usability: An Update for an Internet Age, pp. 103-141. https://doi.org/10.1016/B978-012095811-5/50004-3

[10] Nielsen, J. (1994). Enhancing the Explanatory Power of Usability Heuristics. Proceedings of the SIGCHI Conference on Human Factors in Computing Systems. pp. 152-158. https://doi.org/10.1145/191666.191729

[11] Federoff, M.A. (2002). Heuristics And Usability Guidelines For The Creation And Evaluation Of Fun In Video Games. Indiana University

[12] Desurvire, H., Caplan, M. \& Toth, J.A. (2004). Using Heuristics to Evaluate the Playability of Games. Proceedings CHI 2004 Extended Abstracts on Human Factors in Computing Systems, pp. 1509-1512. https://doi.org/10.1145/985921.986102

[13] Pinelle, D., Street, U. \& Hall, G. (2008). Heuristic Evaluation for Games: Usability Principles for Video Game Design. Proceedings of the SIGCHI Conference on Human Factors in Computing Systems, pp. 14531462

[14] Pinelle, D., Wong, N., Stach, T., Gutwin, C., Street, U., \& Hall, G. (2009). Usability Heuristics for Networked Multiplayer Games. Proceedings of the ACM 2009 International Conference, pp. 169-178

[15] Hochleitner, C., Hochleitner, W., Graf, C. \& Tscheligi, M. (2015). A Heuristic Framework for Evaluating User Experience in Games. Game User Experience Evaluation, $1^{\text {st }}$ Ed. Springer.

[16] Korhonen, H. \& Koivisto, E. M. I. (2006). Playability Heuristics for Mobile Multi-player Games. Proceedings of the 8th Conference on Human-Computer Interaction with Mobile Devices and Services. https://doi.org/10.1145/1306813.1306828

[17] Alhaidary, R. \& Altammami, S. (2017). Can the Success of Mobile Games Be Attributed to Following Mobile Game Heuristics?, In: Meiselwitz G. (eds) Social Computing and Social Media. Human Behavior. SCSM
2017. Lecture Notes in Computer Science, vol 10282. Springer, Cham. https://doi.org/10.1007/978-3-31958559-8_2

[18] Desurvire, H. \& Wiberg, C. (2009). Game Usability Heuristics (PLAY) for Evaluating and Designing Better Games: The Next Iteration. In: Ozok A.A., Zaphiris P. (eds) Online Communities and Social Computing. OCSC 2009. Lecture Notes in Computer Science, vol 5621. Springer, Berlin, Heidelberg. https://doi.org/10.1007/978-3-642-02774-1_60

[19] Mylly, S., Rajanen, M. \& Iivari, N. (2019). Usable Usability Heuristics for Game Developers. In A. Siarheyeva, C. Barry, M. Lang, H. Linger, \& C. Schneider (Eds.), Information Systems Development: Information Systems Beyond 2020 (ISD2019 Proceedings). Toulon, France: ISEN Yncréa Méditerranée.

[20] Johnson, D. \& Scholes, L. (2013). Videogames and wellbeing: A comprehensive review, Young and Well CRC, Melbourne, VIC, Australia

[21] Yuksel, M. (2012). The Positive Psychology of Gaming: Immersion Through Flow in Simulations. Journal of Internet and e-Business Studies, pp. 1-10

[22] Chiang, Y.T., Lin, S.J., Cheng, C.Y. \& Liu, E.Z. (2011). Exploring Online Game Players' Flow Experience and Positive Affect. The Turkish Online Journal of Educational Technology, Vol. 10(1), pp. 106-114

[23] Voiskounsky, A.E. (2010). Internet Addiction in the Context of Positive Psychology. Psychology in Russia State of Art, 3, pp. 541-549

[24] Chou, J.C., Hung, C. \& Hung, Y. (2014). Design Factors of Mobile Game for Increasing Gamer's Flow Experience. Proceedings of 2014 IEEE International Conference on Management of Innovation and Technology. doi:10.1109/icmit.2014.6942414

[25] Kaltum, U., Rimadina, R. \& Zusnita, W. (2018). The Technology Acceptance Model for Playing Mobile Games in Indonesia. Proceedings of The 2018 International Conference of Organizational Innovation, pp. 1022 - 1034

[26] Andersen, E., O’Rourke, E., Liu, Y.E., Snider, R., Lowdermilk, J., Truong, D., Cooper, S. \& Popovic, Z. (2012). The Impact of Tutorials on Games of Varying Complexity. Proceedings of CHI 2012. Austin, Texas, USA

[27] Huang L.Y. \& Hsieh, Y.J. (2011). Predicting Online Game Loyalty Based on Need Gratification and Experiential Motives. Internet Research, Vol. 21(5), pp. 581-598

[28] Kristanto, D. (2018). The Impact of Game Avatar CUstomization in Improving User Experience and Gamer Loyalty. The International Journal of Applied Business, Vol. 2(2).

[29] Bycer, J. (2014). The Importance of Progression Gameplay Models. Diakses dari https://gamewisdom.com/critical/progression-gameplay pada tanggal 20 Juni 2021 


\section{LAMPIRAN 1 \\ DAFTAR KUISIONER}

M. Game harus memiliki mekanisme yang memfasilitasi proses belajar si pemain dan alur permainan secara umum

M1. Game menyediakan tutorial cara bermain di awal permainan

M2. Tutorial cara bermain dapat ditampilkan ulang

M3. Menu BANTUAN sangat jelas dan informatif

M4. Ada kecocokan antara sistem dengan dunia nyata

M5. Cara kontrol permainan dapat dikustom

M6. Sistem dapat mencegah saya melakukan kesalahan dengan memunculkan pesan peringatan

M7. Pemain langsung dilibatkan dalam permainan secara cepat dan mudah

M8. Game memberikan petunjuk atau saran dalam bermain

M9. Manual/petunjuk sebenarnya tidak dibutuhkan untuk memulai permainan

M10. Bagian-bagian dalam game yang memang tidak dapat dimainkan oleh pemain, dapat segera dilewati (skip)

M11. Game menyajikan informasi dalam berbagai format/bentuk

M12. Pemain dapat mengontrol sepenuhnya game ini

K. Game harus mudah dan menyenangkan untuk dimainkan, tetapi memiliki kerumitan untuk mempertahankan keterlibatan pemain

$\mathrm{K} 1$. Tingkat kesulitan game dapat diubah-ubah

$\mathrm{K} 2$. Tersedia banyak goal dari game ini

K3. Game ini sangat berimbang, bisa dimenangkan tapi bukan dengan cara instan

K4. Terdapat keseimbangan antara tantangan, strategi dan kecepatan

K5. Game ini memberikan reward

K6. Pengalaman pertama bermain ini sangat memotivasi untuk bermain terus

K7. Game ini dapat dimainkan berulang-ulang, misal: mengulangi permainan di babak sebelumnya

K8. Untuk memainkan game ini, pemain tidak perlu mengandalkan ingatan

K9. Hasil dari game ini cukup adil bagi pemain

K10. Tidak ada task/tugas yang berulang-ulang atau membosankan

K11. Pemain dapat melihat progress permainan dan dapat membandingkan hasilnya

K12. Tantangan dalam game ini membuat saya tertantang untuk terus bermain, bukan menjadi putus asa dan ingin berhenti bermain

K13. Goal/tujuan yang harus diraih pemain sangat jelas dari awal permainan

F. Pemain harus dapat mengidentifikasi tindakannya dalam permainan dan umpan balik
F1. Pemain dapat melihat progress permainan dan dapat membandingkan hasilnya

F2. Feedback tersedia dalam bentuk suara/audio

F3. Semua feedback muncul seketika itu juga

F4. Feedback diberikan dalam berbagai format/bentuk

G. Game ini harus memiliki grafis yang menarik tanpa mempengaruhi alur permainan dan dapat dikostumisasi

G1. Tampilan antarmuka game ini konsisten dalam hal warna maupun tipografi pada tiap babak

G2. Layout objek-objek dalam game cukup efisien dan enak dipandang

G3. Pemain mudah untuk mengerti atas istilah-istilah dan seni desain yang ada di dalam game

G4. Semua informasi yang relevan ditampilkan di layar

G5. Tampilkan antarmukanya (interface) tidak mengganggu pandangan

G6. Navigasi dalam game cukup konsisten, bisa dilogika, dan minimalis

G7. Alur cerita game ini sangat mendukung permainan dan penuh makna

G8. Efek visual dan audio membangkitkan minat pemain

G9. Audio, video dan grafik dapat dikustom

A. Game harus dapat diakses oleh semua orang atau pemain

A1. Ukuran icon dapat diubah-ubah

A2. Game memiliki pengaturan bahasa

A3. Deskripsi aksi permainan dapat dihidupkan/dimatikan

A4. Pemain tidak dapat membuat kesalahan yang tidak dapat diperbaiki

B. Permainan harus cocok untuk mobilitas

B1. Sesi permainan bisa dimulai dengan segera

B2. Permainan mengakomodasi kondisi lingkungan sekitar

B3. Interupsi dapat dilakukan secara wajar

B4. Pemain dapat dengan mudah mematikan dan menghidupkan game, dan dapat menyimpan game di berbagai kondisi

P. Pemain terhanyut dalam pengalaman bermain game

P1. Saat memainkan game ini, saya selalu fokus total

P2. Saat memainkan game ini, saya selalu merasa waktu berjalan lebih cepat dari biasanya

P3. Saat memainkan game ini, saya selalu mengabaikan halhal di sekitar saya

P4. Saat memainkan game ini, saya seperti menciptakan dunia game virtual, tapi dunia itu akan hilang setelah saya berhenti memainkannya

P5. Saat memainkan game ini, saya tahu tubuh saya ada di dunia nyata tetapi pikiran saya ada di dunia game virtual 